\title{
Dependence of Reliability and Resource of the Elements of the Design of Quarry Automatics with the Degrees of their Downloads
}

\author{
Dmitriy Stenin ${ }^{1 *}$, and Natalya Stenina ${ }^{1}$ \\ ${ }^{1}$ T.F. Gorbachev Kuzbass State Technical University, 650000, 28 Vesennyaya St., Kemerovo, Russia
}

\begin{abstract}
The article discusses the impact of operational factors on the reliability of reducers for motor-wheels of mine dump trucks, the consequences of oil overheating in the reducer are determined. As a result of the research, the degree of influence of various factors on the oil temperature and the dependence of the oil temperature on the coefficient of load capacity have been determined. And also dependence of expenses on repair of reducers of motor-wheels from loading of a dump truck.
\end{abstract}

\section{Introduction}

Coal continues to play a crucial role in the global economy. Coal takes the second place after oil. The growth in Russian coal production 1.5 times from 2000 to 2016 is mainly due to a more economical open-cut mining method, the share of which has increased over this period from 64 to $70,6 \%$. [1]

The global crisis and anti-Russian sanctions have exacerbated the internal and external problems of the domestic coal industry, have formed a range of risks that limit the development of coal-mining regions.

Russia is one of the world's leading producers of coal. There are one third of the world's coal resources and one-fifth of the explored reserves are 193.3 billion tons in its subsoil. [2]

The diagram of coal production in Russia and Kuzbass for 2006-2016 is shown in Figure 1.

The coal production in Russia and the Kuzbass increased at the last 10 years by 75.7 and 53.9 million tons, respectively.

The dump trucks with the carrying capacity of 130-220 tons are the most common at present time. [3]

* Corresponding author: sdv.ea@kuzstu.ru 


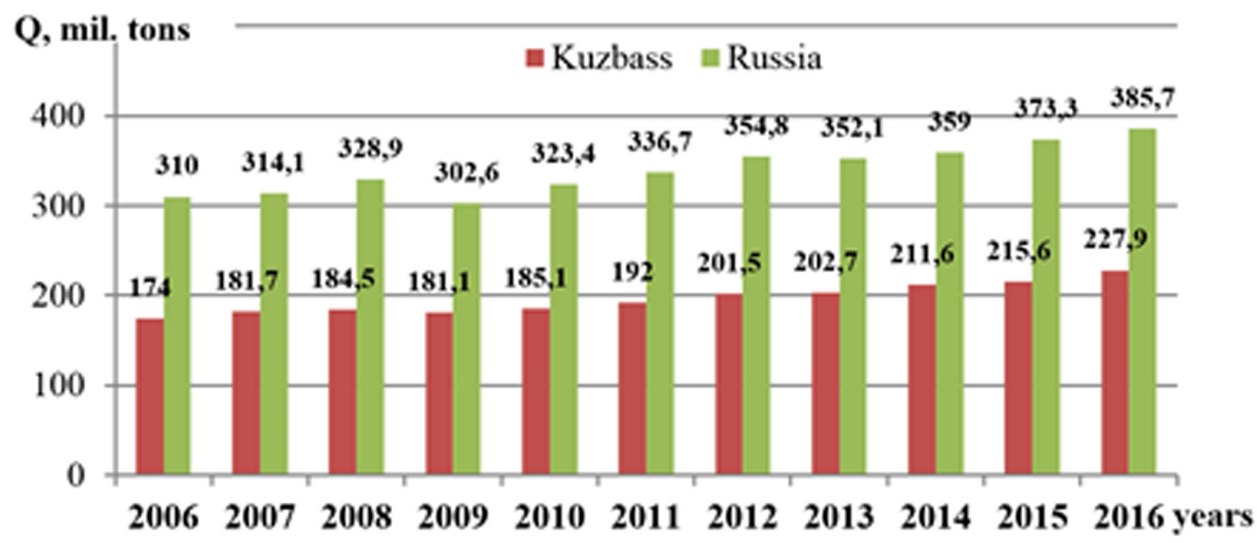

Fig. 1. The coal production in Russia and Kuzbass in 2006-2016.

\section{Materials and methods}

The most unreliable element of the electro-mechanical transmission of mining dump trucks is the motor-wheel reducer (MWR). The idle-times of the dump trucks by reasons of failures of the carrier part are approximately $28 \%$ of the total idle-time and the failures of MWR account for $37 \%$ of they [3]. The temperature mode of the MWR depends on its technical condition. The change of the technical condition of the MWR depends on their operating modes which characterized by operating conditions. In work [3] the temperature mode means the mode of changing the temperature of the MWR oil in time during various operating conditions of mining dump trucks.

The influence of the all variety of operational factors on the reliability of the MWR can be estimated through the indicators of their thermal state. Therefore, for the determine of the thermal state it is necessary to establish the dependence of operating conditions from their technical state [4].

Scientific research began with the formulation of the problem and the experimental researches carried out at the area of the branch of "Taldinskiy coal mine" "Mining Company"Kuzbassrazrezugol".

The purpose of the experimental researches was the determination of the various temperature modes of the mining trucks MWR in different operating conditions at different times of the year.

The research tasks included the study of the temperature of MWR oil through of measuring instruments.

For the experiment were chosen the following variables indicators: - temperature of the oil of the motor-wheel reducer;

- ambient air temperature;

- longitudinal slope of the road;

- length of the route;

- coefficient of load the vehicle.

The all measuring instruments were with a high accuracy and small error. The temperature of the oil was measured at least once a week for several hours.

The main models of dump trucks with electric transmission at the "Taldinskiy coal mine" are the BelAZ-75131, -75302, -75306. Over 90 dump trucks of these models were observed.

The object of the study is MWR (temperature of MWR oil). 
The most actual issues related to the development of modern technology, its reliability and durability are the increasing the technical level and quality of mining machine building products. Intensification of mining operations, increasing the productivity of machines and aggregates, intensive growth of mining production is impossible without the increasing the reliability of technical means of mining enterprises. The experience of mining enterprises shows the reliability of mining equipment is still insufficient and depends on mining, organizational, natural and climatic and operational conditions. [5]

The dependencies of reliability indicators from operating conditions were established in work [6]. The obtained regularities allow controlling the technical state of machines during their operation.

The reliability of dump trucks and other mining equipment depends on their constructive features, manufacturing quality and on factors characterizing operating conditions, such as mining technical factors, the quality of road surfaces, the organization of technical operation processes, modes and quality of maintenance. The issue of increasing the reliability of RMK dump trucks is of great importance.

\section{Results and discussion}

Oil is the most effective, flexible, variable and controlled element. The oil's temperature has the great value in the operation of MWR, because the transmission oil loses its lubricating properties at high temperatures. Because of this, there is an increased wear of gears and bearings in reducers. In practice, the heating of the gearbox is determined by touch, and this often does not provide reliable information.

Studies by various authors show:

1. The intensity of decline in the technical readiness of mine dump trucks is $1,8 \div 3,0 \%$ per year [7];

2. The TAP-15V gear oil is used in MWR of the dump trucks with the carrying capacity of $80 \div 220$ tons at an ambient temperature of $-25^{\circ} \mathrm{C}[7]$.

3. A decrease the reliability of aggregates of mining equipment with a closed lubrication system is due to a worsening the technical condition of the aggregates themselves as a result of wear, a change of the properties of the operating oil. It is possible to determine the violation of the adjustment of the bearings or the change in the oil level in the reducer by the degree of heating. The oil's condition and its parameters change faster than the failure of the technique. This is justified by the fact that before the failure of MWR in oil the content of wear products increases and the oil's temperature increases [8].

4. The operating oil contains the complex information that allows to predict and diagnose the technical condition of the object and to describe the ongoing processes. It makes the opportunity to identify the reasons of the decrease the reliability of the MWR and to estimate them quantitatively [9].

5. The minimum value of the temperature of the MWR oil is $\mathrm{t}_{\mathrm{o}}=95^{\circ} \mathrm{C}(\mathrm{BelAZ}-75306)$, and the average oil temperature $-t_{0}=129^{\circ} \mathrm{C}$ and the maximum temperature $-t_{0}=161^{\circ} \mathrm{C}$ (BelAZ-75302) exceed the critical already at an ambient temperature more than $+15^{\circ} \mathrm{C}$ [3].

6. The actual technical condition of the motor-wheels reducers is estimated by the temperature of the operating oil and the critical value of the oil operation is $120^{\circ} \mathrm{C}$. [8-12]

7. The quantity of failures is reduced by $25 \%$ at deviation the oil temperature from the critical value $\left(120^{\circ} \mathrm{C}\right)$ to the minimum $\left(95^{\circ} \mathrm{C}\right)$, and increases by 9 times with increasing to a maximum value $\left(161^{\circ} \mathrm{C}\right)$.

As a result of data processing, the cost ratio for repairing the MWR and the mean temperature of the oil in the reducer was established (Fig. 2). 


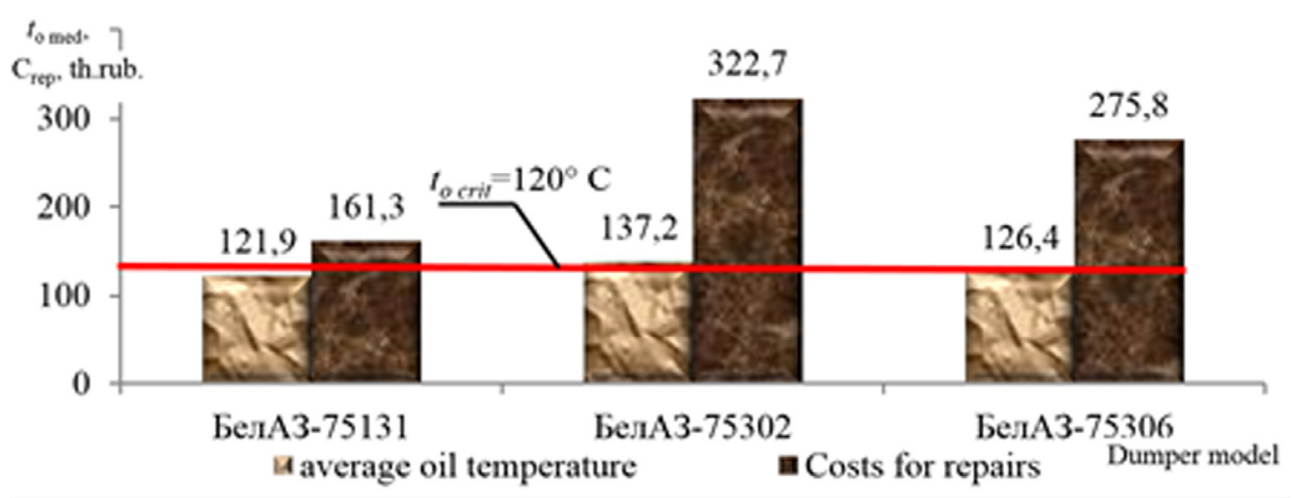

Fig. 2. The value of the average oil temperature and repair costs per one dump truck.

The average temperature of the MWR oil has the maximum values for the BelAZ-75302 quarry dump truck $\left(137,{ }^{0} \mathrm{C}\right)$, the repair costs of the MWR are the highest for the same model of dump truck.

It is established the temperature regime of motor-wheels reducers objectively evaluates their technical condition through reliability indicators: the number of failures, the availability factor and the operating cost factor.

The most indicative index for determining the rational load-carrying capacity coefficient (LCC) is the unit cost of repairs, which allow the influence of the LCC at the efficiency of dump trucks and on the cost of repairing the reducer.

The procedure for determining the rational loading of mining dump trucks with considering the temperature regime of the MWR at the minimum unit cost of repair is as follows:

The unit cost of repairs costs are determined by the formula:

$$
C_{u n}=\frac{C_{r e p}}{Q_{y}}, \mathrm{rub} / \mathrm{t},
$$

where $C_{u n}$ - annual costs for repair of RMK, rubles / year .; $Q_{y}$ - annual efficiency, t/year. formula:

The temperature of MWR oil for all models of dump trucks is determined by the

$$
t_{o}=70,83+27,09 \cdot \gamma_{l}+1,04 \cdot t_{a m}+0,38 \cdot L_{c c}+1,43 \cdot i,{ }^{\circ} \mathrm{C}
$$

where $\gamma_{l}$ - load-carrying capacity coefficient.

Annual efficiency $\left(\mathrm{Q}_{\mathrm{y}}\right)$ is determined by the formula $[10]$ :

$$
Q_{y}=Q_{h} \cdot T_{w}
$$

where $Q_{h}$ - is the hourly efficiency of the truck, t/hour; $T_{w}$ - working time per year, hours.

The hourly efficiency of the truck is determined by the formula:

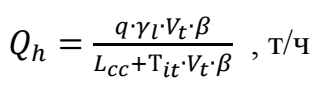

where $\mathrm{q}$ - the carrying capacity of the truck, $\mathrm{t} ; \gamma_{l}$ - load-carrying capacity coefficient; $V_{t}$ - technical speed, $\mathrm{km} / \mathrm{h} ; L_{c c}$ - length of the carriage with a load, $\mathrm{km} ; \mathrm{T}_{i t}$ - idle time of a dump truck for one flight, $\mathrm{h} ; \beta$ - the mileage utilization factor.

The coefficient of readiness is determined by the formula [5]:

$$
k_{r}=\frac{D-Д_{r e p}}{D}
$$

The coefficient of operating costs Koc is determined by the formula [5]: 


$$
k_{o c}=\frac{C_{r e p}}{C_{\mathrm{MWR}}},
$$

where $C_{r e p}$ - the cost of maintenance before the repair which consist of the costs of repair on maintenance and costs on the fault rectification; $\mathrm{C}_{\mathrm{MWR}}$ - the cost of MWR.

The relation of unit costs on the load-carrying capacity coefficient is shown in the graph in Fig. 3.

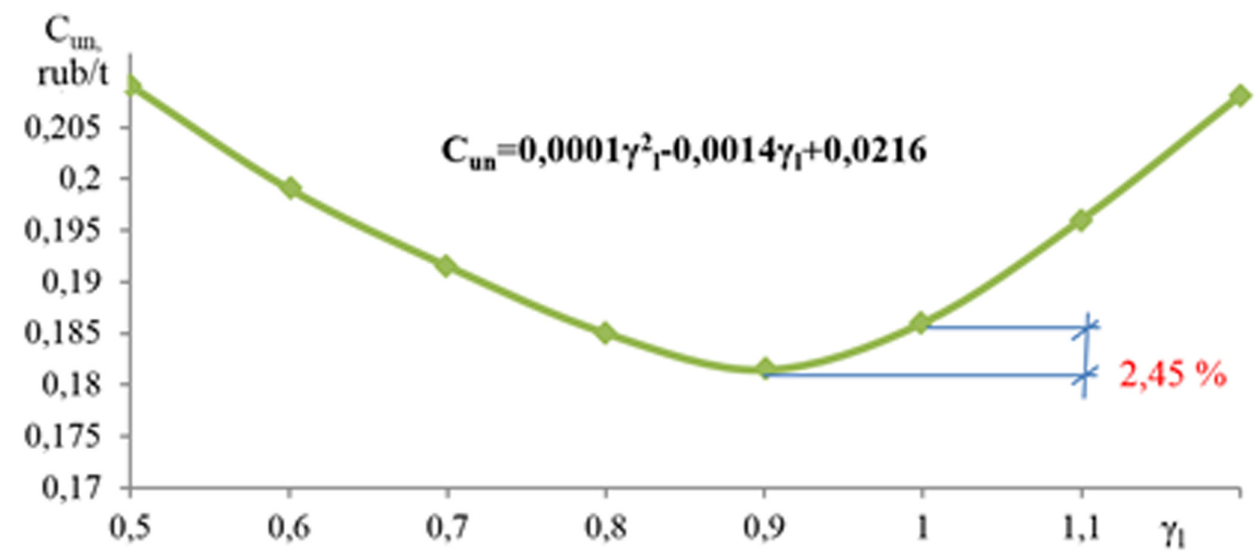

Fig. 3. relation of unit costs $\left(\mathrm{C}_{\mathrm{un}}\right)$ on the load-carrying capacity coefficient $\left(\gamma_{1}\right)$.

Thus, the rational load-carrying capacity factor during operation dump trucks under these conditions is 0,9 . Wherein, the oil temperature increased by $3 \%$, the duration time in the repair for the year did not change; the coefficient of readiness decreased by $0,1 \%$, but thanks to the growth of the efficiency unit costs decreased by $2,45 \%$.

It should be noted that in each case the value of the rational load-carrying capacity coefficient is a different and it depends on the operating conditions.

\section{Conclusion}

We can to make the following conclusions based on the foregoing:

1. The relations of unit costs, number of failures and days in the repair of oil temperature in the MWR of dump trucks are exponential $\mathrm{n}_{\mathrm{f}}=0,0034 \cdot \mathrm{e}^{\wedge}\left(0,055 \cdot \mathrm{t}_{\mathrm{o}}\right), \mathrm{D}_{\text {rep }}=0,0093 \cdot \mathrm{e}^{\wedge}\left(0,0555 \cdot \mathrm{t}_{\mathrm{o}}\right)$; $\mathrm{C}_{\text {rep }}=967,29 \cdot \mathrm{e}^{\wedge}\left(0,043 \cdot \mathrm{t}_{\mathrm{o}}\right)$

2. At oil's temperature deviation from the critical value of $120^{\circ}$ to the minimum of $95^{\circ}$, the number of failures is reduced by $25 \%$ and at increasing to a maximum value $161^{\circ}$ - increases by 9 times.

3. The relation of unit costs on the load-carrying capacity coefficient is parabolic, which has a minimum value for the rational coefficient and is described by the equation: $\mathrm{C}_{\mathrm{un}}=\mathrm{a} \cdot \gamma^{2}{ }^{-}$ $\mathrm{b} \cdot \gamma_{1}+\mathrm{c}$.

4. The rational value of the the load-carrying capacity coefficient with considering the temperature mode of the MWR and operating conditions is selected at the minimum of unit costs which taking into account the productivity and reliability of mine dump trucks. The number of failures is reduced by $25,7 \%$, the cost of repairing the MWR by $20,8 \%$, the temperature of the MWR oil by $3,21 \%$ (from $140,4^{\circ} \mathrm{C}$ to $135^{\circ} \mathrm{C}$ ) when decreasing the load-carrying capacity coefficient to 0,8 [3-16].

5. The operating conditions of vehicles reduce performance, reliability and, as a consequence, increase the cost of the obtained final product and makes the increased demands on the fuels and lubricants used in operation. 
6. On the one hand, an increase a LCC leads to an increase in productivity. But only hourly, shift or daily, i.e. for a short period of time, when the reliability of the MWR is not yet affected by the performance value. On the other hand, an increase of the load-carrying capacity coefficient (and, in some cases, the overload of dump trucks) leads to an increase of the oil temperature in the MWR. And as a result, their reliability decreases, the number of failures, repair costs and coefficient of readiness increases.

7. The criterion for choosing a rational load-carrying capacity coefficient is as follows: $\frac{C_{r e p}}{Q_{y}}=$ $\min \rightarrow \gamma_{l}^{r a t}$.

8. If we know the relation of the idle time of the dump trucks in the repair $\mathrm{D}_{\text {rep }}$ (because of the failure of the reducers) from the oil temperature in the MWR $t_{0}$ we can to obtain the relation $D_{\text {rep }}=f\left(\gamma_{1}\right)$ with the help of the presented equations. And, thus, we can to determine the most rational load-carrying capacity coefficient in which the duration of downtime in repairs and repair costs will be minimal and the productivity of dump trucks the maximum.

Thus, the smaller the loading rate of the truck, the better the listed performance indicators. However, with a significant underload of dump trucks, their productivity is significantly reduced.

Therefore, the determination of the degree of loading in this sequence according to the proposed procedure is appropriate.

\section{References}

1. A.I. Kopytov, Ugol', 3, 72 (2017)

2. I.G. Tarazanov, Coal, 3, 36 (2017)

3. N.A. Stenina, The influence of operating conditions on the temperature regime of motor-wheel reducer of mining dump trucks. Scientific theses (Kemerovo, KuzSTU, 2013)

4. S.A. Bogdanov, The development of a method for determining the change in the technical state of vehicle transmission aggregates in terms of their thermal state: abstract of scientific theses, (Kharkov, UIAN, 1987)

5. A.A. Khoreshok, G.D. Buyalich, E.V. Preis, M. Yu. Blashchuk, The reliability of mining machines and equipment: Schoolbook, (Tomsk: TPU Publishing House, 2008)

6. N.V. Zyryanov, Determination of the influence of dynamic loads on the resource of mining dump trucks: abstract of scientific theses, (St. Petersburg, SPbMU, 1995)

7. V.A. Ametov, The development of ways to improve the reliability of vehicle transmission units in terms of operating oil parameters: Scientific theses, (Kemerovo, KuzSTU, 1987)

8. A.V. Kudrevatykh, Justification of methods and parameters for diagnosing reducers of excavator-car complexes: Scientific theses, 187 (Kemerovo, KuzSTU, 2010)

9. N.V. Ababkov, KuzSTU Bul. 1, 129 (2016)

10. D.V. Stenin, Justification of the influence of the resource of bearing systems and the degree of loading on the performance of mining dump trucks: Scientific theses, (Kemerovo, KuzSTU, 2008)

11. D.V. Stenin, N.A. Stenina, A.P. Stolyarova, Sci. Alm. 9:23, 501 (2016)

12. D.V. Stenin, N.A. Stenina, Autom. Ind., 10, 26 (2012)

13. A.S. Furman, D.V. Stenin, V.E. Ashikhmin, KuzSTU Bul. 5, 92 (2007)

14. D. Basset, M. Herman, J. M. Martin, ASLE Transactions, 27:4, 380 (1984) 
15. Pearse Geoff, Min. Mag., 128 (1987)

16. Q.Sunqing, D. Junxiu, Ch. Guoxu, Lubr. Sci. 11:3, 165 (1999) 
